\title{
Crestal Bone Loss Around Submerged and Non-Submerged Dental Implants in Individuals with Type-2 Diabetes Mellitus: A 7-Year Prospective Clinical Study
}

\author{
Saeed Al Zahrani ${ }^{a} \quad$ Abdullah A. Al Mutairi ${ }^{b}$ \\ a Division of Prosthodontics, Department of Dental Services, Central Region, King Abdulaziz Medical City, \\ Ministry of National Guard Health Affairs, Riyadh, Saudi Arabia; 'b Division of Advanced Education in General \\ Dentistry, Department of Dental Services, Central Region, King Abdulaziz Medical City, Ministry of National \\ Guard Health Affairs, Riyadh, Saudi Arabia
}

\section{Significance of the Study}

- In establishing an evidence-based rationale for the optimal use of implant therapy for patients with type 2 diabetes mellitus (T2DM), it is essential to first understand the impact of glycemic control on early healing and the success of dental implants in the Saudi population. The high prevalence of diabetes mellitus in Saudi Arabia has led us to investigate peri-implant bone outcomes in individuals with poorly controlled and well-controlled diabetes.

\section{Keywords}

Alveolar bone loss · Dental implants · Diabetes mellitus . Resonance frequency analysis

\footnotetext{
Abstract

Objective: In establishing an evidence-based rationale for the optimal use of implant therapy in patients with type 2 diabetes mellitus (T2DM), it is essential to first understand the impact of glycemic control on early healing and the success of dental implants. The objective of this study was to evaluate crestal bone loss (CBL) and stability around submerged and non-submerged dental implants in Saudi patients with well- and poorly controlled T2DM. Subject and Methods: Thirty-five patients with well-controlled T2DM (24 males and 11 females) and 32 poorly controlled T2DM patients (19 males and 13 females) were included. CBL was measured on digital radiographs; resonance frequency anal-
}

ysis (RFA) measurements were made for each implant at the time of fixture placement and at 3 months in both the groups. A $p$ value less than 0.05 was considered statistically significant. Results: A total of 124 dental implants were placed. Mean RFA values between baseline and 3 months in poorly controlled T2DM patients was statistically significant ( $p=$ $0.048)$. CBL at first year ( $p=0.047)$, second year $(p=0.041)$, third year $(p=0.046)$, and seventh year $(p=0.035)$ was significantly worse in poorly controlled T2DM. CBL around nonsubmerged dental implants showed statistically significant differences at all time-intervals $(p<0.05)$. Conclusion: Poorly controlled T2DM patients present worse peri-implant bone outcomes as compared to patients with well-controlled T2DM. We suggest that the predictability of successful dental implant therapy outcomes depends on the maintenance of optimal haemoglobin A1c levels.

(c) 2018 The Author(s) Published by S. Karger AG, Basel

\begin{tabular}{|c|c|c|}
\hline KARGER & $\begin{array}{l}\text { (c) } 2018 \text { The Author(s) } \\
\text { Published by S. Karger AG, Basel }\end{array}$ & $\begin{array}{l}\text { Karger } \\
\text { Open access }\end{array}$ \\
\hline $\begin{array}{l}\text { E-Mail karger@karger.co } \\
\text { www.karger.com/mpp }\end{array}$ & $\begin{array}{l}\text { This is an Open Access article license } \\
\text { Attribution-NonCommercial- }-4.0 \text { Int } \\
\text { (http://www.karger.com/Services/Op } \\
\text { the online version of the article on } \\
\text { commercial purposes requires writte }\end{array}$ & $\begin{array}{l}\text { the Creative Commons } \\
\text { al License (CC BY-NC) } \\
\text { ssLicense), applicable to } \\
\text { ge and distribution for } \\
\text { ission. }\end{array}$ \\
\hline
\end{tabular}

Dr. Saeed Al Zahrani

Consultant Prosthodontics Division, Department of Dental Services Central King Abdulaziz Medical City, Ministry of National Guard Health Affairs P.O. Box 22490, Riyadh 11426 (Saudi Arabia)

E-Mail saeedalzahrani@gmail.com 


\section{Introduction}

Type 2 diabetes mellitus (T2DM) is a complex endocrine disorder characterized by chronic hyperglycemia that results in the inability of glucose uptake by cells due to impaired action of insulin [1]. Glycosylated haemoglobin $\mathrm{A} 1 \mathrm{c}(\mathrm{HbA1c})$ is the most reliable means of evaluating chronic glycemia [2]. An HbA1c value that corresponds $\leq 6.0 \%$ represents a well-controlled type 2 diabetes, while an $\mathrm{HbAlc}$ value $>10.0 \%$ represents a poorly controlled T2DM [3]. Recent data from the World Health Organization reveals that an estimated 7 million adults have diabetes mellitus and more than 3 million are prediabetic in Saudi Arabia [4]. Saudi Arabia has the seventh highest rate of T2DM in the world and second highest in the Middle East [4].

Diabetes mellitus is an extremely important disease from the stand point of dental implant therapy. It is wellknown that chronic hyperglycemic state impairs periodontal structure and functions, which may directly impact the integrity of the periodontium and hence the read for dental implant therapy $[5,6]$. This is particularly true for patients whose diabetes is poorly controlled, whereas diabetic patients whose disease is well controlled experience few complications. Evidence suggests that T2DM impairs the structure and function of collagen, which may directly impact the integrity of the periodontal tissues [7, 8]. Chronic hyperglycemia adversely affects the synthesis, maturation, and maintenance of collagen and extracellular matrix [9]. In the hyperglycemic state, numerous proteins and matrix molecules undergo a nonenzymatic glycosylation, resulting in accumulated glycation end-products (AGEs). The formation of AGEs occurs at normal glucose levels as well, but in hyperglycemic environments, AGE formation is excessive [10].

Factors influencing successful implant therapy for patients with T2DM remain unclear particularly due to limited information available on the influence of glycemic control on implant success. Although clinical and radiographic outcomes of submerged and non-submerged dental implants in non-diabetic individuals have been thoroughly investigated $[11,12]$, data on peri-implant outcomes around submerged and non-submerged dental implants in patients with well- and poorly controlled T2DM are limited and controversial. Recent findings show that dental implants may also be successfully placed in poorly controlled diabetic patients with similar success rates as seen in well-controlled diabetic individuals $[13,14]$. In establishing an evidence-based rationale for the optimal use of implant therapy for patients with
T2DM, it is essential to first understand the impact of glycemic control on early healing and success of implants. Therefore, the aim of this 7-year prospective study was to evaluate crestal bone loss (CBL) and stability around submerged and non-submerged dental implants in Saudi patients with well- and poorly controlled T2DM.

\section{Subjects and Methods}

\section{Ethical Guidelines}

The study was performed in accordance with the Declaration of Helsinki as revised in 2013 for experimentation involving human subjects. This was a 7 -year prospective observational study designed, conducted and reported following "Strengthening The Reporting of OBservational Studies in Epidemiology" (STROBE) checklist [15]. The clinical trial was conducted at King Abdulaziz Medical City, Dental Centre, Riyadh, Saudi Arabia. The study protocol was approved by the Ethics Committee of King Abdullah International Medical Research Center, Saudi Arabia.

\section{Recruitment of Study Participants}

This prospective clinical study was performed at King Abdulaziz Medical City, Dental Centre, Riyadh, Saudi Arabia between July 2009 and May 2011. Male and female patients were recruited from the National Guard community, Riyadh, Saudi Arabia. Eligible participants were informed about the purpose and process of the study in Arabic or in English orally and in writing. The study subjects signed a consent form and were allowed to resign from the research project at any point with no consequences. All participants who self-reported to have T2DM were requested to present their medical records for verification of HbAlc.

\section{Inclusion and Exclusion Criteria}

Adult patients diagnosed with (i) well-controlled T2DM (HbA1c levels $\leq 6.0 \%$ ) according to the American Diabetes Association [1], controlled by diet and anti-diabetic drugs (with or without insulin) and poorly controlled T2DM (HbA1c levels $>8.0 \%$ ) not controlled by diet and anti-diabetic drugs at the time of surgery; (ii) replacing single missing tooth with; (iii) adequate bone dimensions for implant placement without bone grafting and; (iv) implant sites with $\geq 3$ months of healing were recruited. Patients with medical conditions other than T2DM, periodontal disease, smoking habits, and who had used steroids, non-steroidal anti-inflammatory drugs or antibiotics within the previous 6 months were excluded.

\section{Measurement of Hemoglobin A1c Levels}

In all patients, $\mathrm{HbA1c}$ levels were investigated using ion-exchange high-performance liquid chromatography and expressed as percentages.

\section{Questionnaire}

Information regarding gender, age, duration of diabetes, type of medication used to control diabetic condition, previous complications due to diabetic condition, and daily oral hygiene status was collected.
Al Zahrani/Al Mutairi 


\section{Surgical Procedure}

A total of 124 dental implants $\left(\right.$ ITI $^{\circledR}$ Straumann Dental Implant System, Wandenburg, Switzerland) were placed in 67 patients with T2DM in the implant clinic between 2009 and 2011 by one surgeon in all the patients. The surgeon was blinded to both the study groups. All implants were placed according to the manufacturer's instructions. A traditional 2-stage surgical protocol was used for submerged implant placement and one-stage surgical protocol for non-submerged implant placement. All surgical procedures were performed under local anesthesia. A crestal incision was made followed by a full-thickness mucoperiosteal flap elevation. After the implant sites were prepared, all implants were placed using a torque controller. The mucosa was sutured after the implant placement. Some implants were placed with a submerged protocol and topped with a closure screw to avoid loading during the healing process, while some were placed with a non-submerged protocol, where the cover screw around the soft tissue was left exposed. The implants were left to heal for 3 months in the mandible and for 6 months in the maxilla for osseointegration. The healing abutments were placed in the second stage. Final impressions were made, and the crowns were fabricated using traditional laboratory methods. A total of 110 single crowns were cement-retained and only 14 were screw-retained. After implant insertion, radiographs were taken at the moment of prosthetic placement following standardized parameters to compare crestal bone levels at 1 year (Fig. 1) and 7-year follow-up (Fig. 2).

\section{Postoperative Care}

After implant placement and suturing, each patient received Augmentin 625 and $400 \mathrm{mg}$ of Ibuprofen to be taken thrice daily for 7 days, with a mouth rinse including $0.2 \%$ chlorhexidine $\left(\right.$ Deef $^{\circledR}$, AlQassim, Saudi Arabia) prescribed to the patients starting the day after the surgery and continued for 2 weeks. Patients were also asked to brush gently with an antiseptic toothpaste. Sutures were removed 8-10 days after surgery. The patients were recalled at 1,2,3, and 7 years after placement of implants. The criteria for success of the implants were stable implants and superstructures with no symptoms of pain and without signs of inflammation and purulent discharge, loss of no more than $1 \mathrm{~mm}$ bone around the implant in the first year, and radiolucency around implants [16].

\section{Resonance Frequency Analysis Measurements}

Resonance frequency analysis (RFA) measurements were made for each implant at the time of fixture placement and at 3 months by one blinded examiner. As described previously by Meredith et al. [17]. Measurements were carried out by screwing a transducer to the top of the abutment. The transducer beam comprised a small L-shaped cantilever to which 2 piezo-ceramic elements had been attached. One of the elements was excited by a sine wave signal of amplitude $1.0 \mathrm{~V}$, which was varied in frequency from 6 to $12 \mathrm{kHz}$ in steps of $25 \mathrm{~Hz}$. The response of the beam was measured by the second piezo-ceramic element and the resonance frequency of the transducer/implant system was calculated from the peak amplitude of the signal.

\section{Crestal Bone Loss}

CBL was defined as the distance from the widest supracrestal part of the implant to the alveolar crest [18]. Digital intraoral radiographs were taken using the long-cone paralleling technique

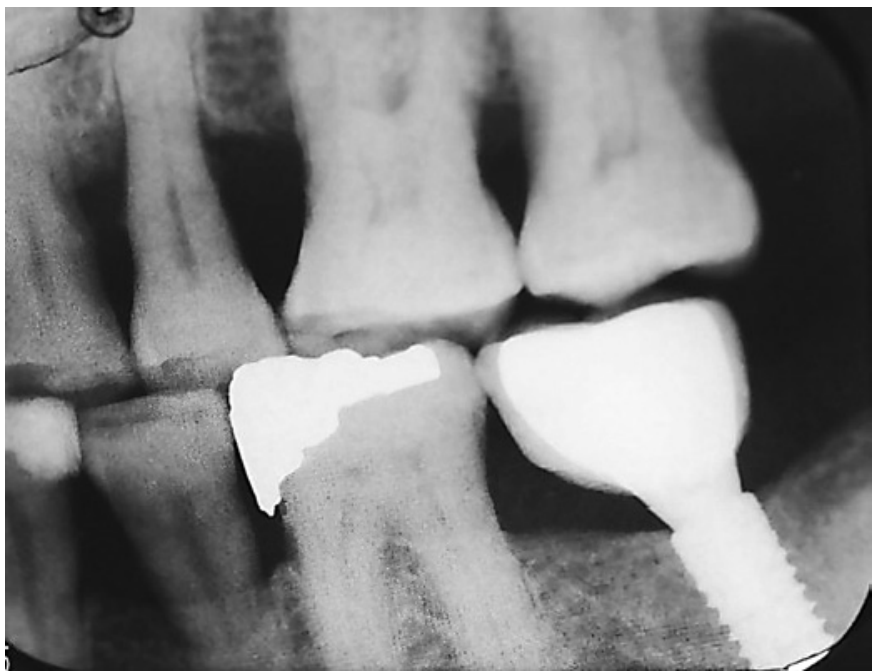

Fig. 1. Crestal bone loss (CBL) around dental implant at 1-year follow-up.

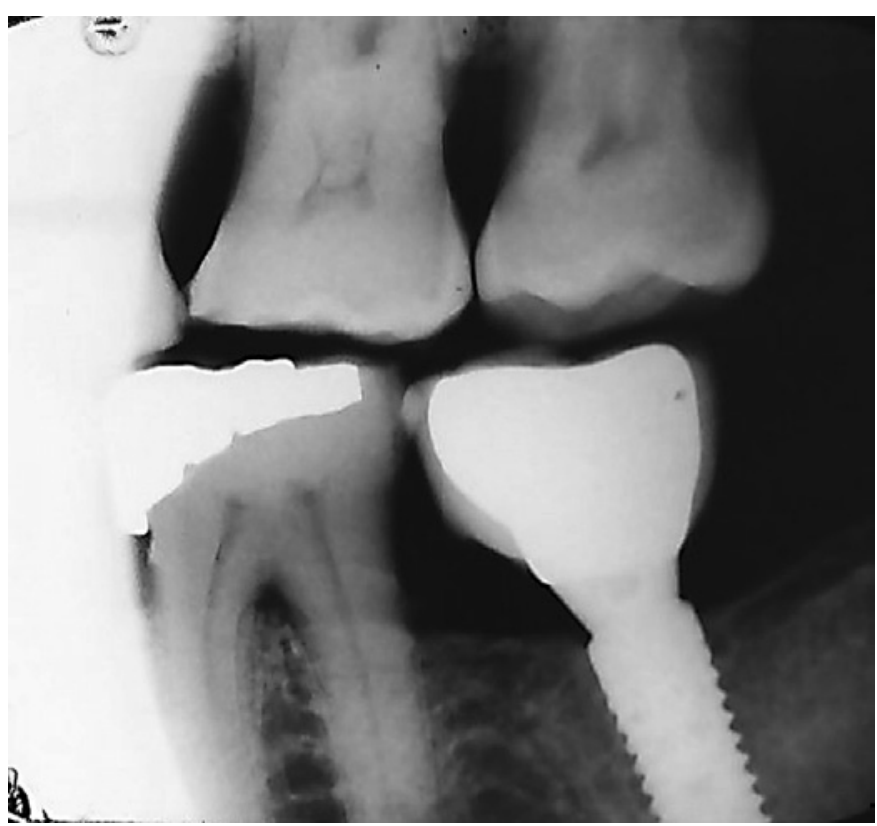

Fig. 2. Crestal bone loss (CBL) around dental implant at 7-year follow-up.

and recorded by one trained examiner who was blinded to the study groups. Intra-examiner reliability was performed by evaluating kappa scores that resulted in good agreement (kappa $=0.83$ ). Patients were seated upright with the Frankfort plan parallel to the floor; and to prepare parallel radiographs, a film holder (Dentsply Rinn, PA, USA) was used to standardize the angulation between the X-ray beam and the film. The central X-ray beam was directed perpendicular to the film and long axis of the implant. In the implant sites, both mesial and distal CBL were analyzed at $20 \times$ mag- 
Table 1. Demographic characteristics of the study sample according to HbA1c levels

\begin{tabular}{|c|c|c|}
\hline Characteristics & $\begin{array}{l}\text { Well-controlled } \\
\text { T2DM }(\mathrm{HbA} 1 \mathrm{c} \\
\text { levels } \leq 6.0 \%)\end{array}$ & $\begin{array}{l}\text { Poorly con- } \\
\text { trolled T2DM } \\
\text { (HbA1c levels } \\
>8.0 \%)\end{array}$ \\
\hline Number of patients & 35 & 32 \\
\hline Gender, male/female & $24 / 11$ & $19 / 13$ \\
\hline Age, years, mean $\pm S D$ & $54.6 \pm 9.9$ & $53.8 \pm 7.9$ \\
\hline Duration of diabetes, years & 6.6 & 11.8 \\
\hline \multicolumn{3}{|l|}{ Daily tooth brushing, \% } \\
\hline Once & 32 & 59 \\
\hline Twice & 68 & 41 \\
\hline
\end{tabular}

nification using computer software (CorelDraw 11.0, Corel Corp. and Coral Ltd., Ottawa, Canada). For calibration, Scion Image computed the minimum and maximum pixel values of 16-bit images and was automatically set up on a linear density calibration function that provided an approximation of the original 16-bit pixel values.

\section{Statistical Analysis}

Statistical analyses were carried out using statistical software (SPSS, version 20.0 for Windows, IBM, Chicago, IL, USA). Data were expressed as means and SDs. The normality of distribution of the variables was tested with Kolmogorov-Smirnov and Shapiro-Wilk tests and confirmed with Q-Q plots. For the purpose of analysis, we divided the patients into subgroups according to HbA1clevels and position of fixture (submerged/non-submerged). CBL was analyzed to identify any associations with $\mathrm{HbAlc}$ levels and position of fixture and the time following implant placement $(1,2,3$, and 7 years). Between-group comparison of means was verified with Mann Whitney $U$ test. The level of significance was set at 0.05 .

\section{Results}

The study groups consisted of 35 patients with wellcontrolled T2DM (24 males and 11 females) and 32 poorly controlled T2DM patients (19 males and 13 females) who received dental implants. Average age did not show statistically significant difference between the 2 groups. The age of the patients ranged between 34 and 75 years. With regard to gender distribution, both the groups showed higher prevalence of men than women. The duration of diabetes was significantly higher in poorly controlled T2DM as compared to well-controlled T2DM. Tooth brushing twice daily was reported by $68 \%$ of the well-controlled patients and by $41 \%$ poorly controlled T2DM patients (Table 1).
A total of 124 dental implants of $10-12 \mathrm{~mm}$ of mean height and 3.3-4.1 $\mathrm{mm}$ of diameter were placed. Sixtyeight single dental implants were restored in mandible, while 56 single implants were inserted in maxilla (Table 2). Of the 124 implants evaluated, 123 (99.1\%) implants survived till 7 years. The one implant failure was an early one, occurring at 6 months following placement. This implant was successfully replaced and restored without further complications, and was evaluated at 1, 2, 3, and 7 years.

The comparison of the mean RFA values between baseline and 3 months in well-controlled T2DM was not statistically significant $(p>0.05)$. Poorly controlled T2DM subjects showed statistically significant ISQ from baseline to 3 -months implant stability $(p=0.048$ ). The inter-group mean RFA values between baseline and 3 months were not significant $(p>0.05)$ (Table 2).

It should be noted that CBL was found to increase in relation to high HbA1c levels. Levels in the well-controlled group varied from $0.25 \mathrm{~mm}$ after the first year, reaching $0.60 \mathrm{~mm}$ after 7 years, while in poorly controlled T2DM (high levels of blood sugar), CBL values increased from $0.48 \mathrm{~mm}$ after 1 year to $1.12 \mathrm{~mm}$ at the end of the 7 years (Table 3). CBL was statistically and significantly different between poorly controlled and well-controlled T2DM at all follow-up periods $(p<0.05)$.

Table 4 shows CBL around submerged and non-submerged dental implants at the 1,2,3, and 7 year follow-up between well- and poorly controlled T2DM. The comparison between submerged dental implants did not show significant difference at any point (Table 4). However, non-submerged dental implants showed statistically significant differences at all 4 time points $(p<0.05)$.

\section{Discussion}

The aim of this 7-year prospective study was to evaluate the CBL and stability around submerged and nonsubmerged dental implants in Saudi patients with welland poorly controlled T2DM. To the best of our knowledge from indexed literature, this is the first study to evaluate CBL and stability around submerged and nonsubmerged dental implants placed in well- and-poorly controlled T2DM patients. The findings of the present study showed that CBL was significantly greater in poorly controlled T2DM patients as compared to well-controlled T2DM patients. Moreover, non-submerged dental implants showed significant bone loss in poorly controlled T2DM patients.
78

Med Princ Pract 2019;28:75-81 DOI: $10.1159 / 000495111$
Al Zahrani/Al Mutairi 
Table 2. Location, position, and stability of dental implants at baseline and 3 months follow-up

\begin{tabular}{|c|c|c|c|c|c|c|c|}
\hline $\begin{array}{l}\text { Poorly controlled T2DM (HbA1c levels }>8.0 \% \text { ) } \\
p \text { value }^{\dagger}\end{array}$ & 22 & 28 & 28 & 29 & $\begin{array}{l}74.80 \pm 7.5 \\
0.70\end{array}$ & $\begin{array}{l}78.66 \pm 6.5 \\
0.79\end{array}$ & $0.048^{*}$ \\
\hline
\end{tabular}

Means of the resonance frequency analysis (RFA) are expressed in implant stability quotient (ISQ).

${ }^{\dagger}$ Intergroup $p$ value; ${ }^{\ddagger}$ intragroup $p$ value. ${ }^{*}$ Denotes statistically significant $p$ value obtained by Mann-Whitney U test.

Table 3. Crestal bone loss between well- and poorly controlled T2DM at 1, 2, 3, and 7 years follow-up

\begin{tabular}{|c|c|c|c|c|}
\hline \multirow[t]{2}{*}{ Groups } & \multicolumn{4}{|l|}{$\mathrm{CBL}, \mathrm{mm}$} \\
\hline & 1-year & 2-year & 3-year & 7-year \\
\hline $\begin{array}{l}\text { Well-controlled T2DM } \\
\text { (HbA1c levels } \leq 6.0 \%)\end{array}$ & $0.25 \pm 0.35$ & $0.31 \pm 0.22$ & $0.44 \pm 0.31$ & $0.60 \pm 0.18$ \\
\hline $\begin{array}{l}\text { Poorly controlled T2DM } \\
\text { (HbA1c levels }>8.0 \% \text { ) }\end{array}$ & $0.48 \pm 0.66$ & $0.64 \pm 0.72$ & $0.83 \pm 0.92$ & $1.12 \pm 0.87$ \\
\hline$p$ value & $0.047^{*}$ & $0.041^{*}$ & $0.046^{*}$ & $0.035^{*}$ \\
\hline
\end{tabular}

* Denotes statistically significant $p$ value obtained by Mann-Whitney U test.

Table 4. Crestal bone loss between submerged and non-submerged dental implants at 1, 2, 3, and 7 years followup

\begin{tabular}{|c|c|c|c|c|}
\hline \multirow[t]{2}{*}{ Groups } & \multicolumn{4}{|c|}{ Crestal bone loss, $\mathrm{mm}$} \\
\hline & 1-year & 2-year & 3-year & 7-year \\
\hline \multicolumn{5}{|l|}{ Well-controlled } \\
\hline Submerged implants & $0.23 \pm 0.34$ & $0.34 \pm 0.52$ & $0.41 \pm 0.71$ & $0.59 \pm 0.72$ \\
\hline Non-submerged implants & $0.25 \pm 0.19$ & $0.51 \pm 0.34$ & $0.62 \pm 0.31$ & $0.55 \pm 0.55$ \\
\hline \multicolumn{5}{|l|}{ Poorly controlled } \\
\hline Submerged implants & $0.28 \pm 0.26$ & $0.36 \pm 0.43$ & $0.46 \pm 0.65$ & $0.66 \pm 0.73$ \\
\hline Non-submerged implants & $0.36 \pm 0.40$ & $0.73 \pm 0.56$ & $0.92 \pm 0.58$ & $1.07 \pm 0.71$ \\
\hline \multicolumn{5}{|l|}{$p$ value } \\
\hline Submerged implants & 0.056 & 0.073 & 0.069 & 0.055 \\
\hline Non-submerged implants & 0.015 & 0.025 & 0.027 & 0.005 \\
\hline
\end{tabular}

Bold font indicates significant $p$ value $(p<0.05)$ between both groups.

Dental implants have been shown to be an effective restorative treatment for missing teeth. The success and survival rates may be dependent on several local and systemic factors, of which T2DM has received considerable attention with regards to the osseointegration between dental implants and alveolar bone $[13,14,19,20]$. Some
T2DM patients neglect their systemic well-being, representing HbAlc levels greater than $8.0 \%$ in the serum [21]. The present study assessed bone loss around dental implants in relation to the metabolic parameter $\mathrm{HbAlc}$, and the findings corroborate with other studies which demonstrated that chronic hyperglycemia may lead to chang- 
es in bone function [22, 23]. A possible explanation for increased crestal bone resorption may be explained by excessive proinflammatory responses through the expression of increased proinflammatory cytokines such as interleukin (IL)- 6 and IL-1 $\beta$, matrix metalloproteinase and tumor necrosis factor alpha in the gingival crevicular fluid and saliva in systemic diseases including T2DM patients $[24,25]$.

It is well known that bone tissue can mount a proinflammatory reaction [26]. The expression of increased cytokines may bring about alterations in bone physiology through increased osteoclastic and decreased osteoblastic activity [27]. This may increase the amount of bone resorption as seen in the present study in which patients with poorly controlled T2DM showed statistically significant difference as compared to well-controlled T2DM patients. Furthermore, evidence suggests that patients with poor $\mathrm{HbA1c}$ levels have augmented levels of AGEs in the serum and peri-implant crevicular fluid in T2DM patients $[10,28]$. For this reason, control and maintenance of glycemic levels should be a key element in the overall care of patients with T2DM, and could play an important role in ensuring the success of implant therapy.

Other critical factors that govern alveolar bone health are duration of diabetes and oral hygiene maintenance. It is noteworthy that all well-controlled T2DM patients reported duration of diabetes of $\sim 7$ years. This is in contrast to the duration of diabetes in poorly controlled patients who had been diabetic for the past $\sim 12$ years. Also, noteworthy that $68 \%$ of well-controlled T2DM patients brushed their teeth twice as compared to only $41 \%$ of poorly controlled T2DM patients. It is therefore speculated that well-controlled T2DM individuals followed proper oral daily oral hygiene maintenance protocols, and as a result, their overall alveolar bone status did not change as much as it changed in patients with poorly controlled diabetes. Numerous studies have showed that peri-implant bacteria and their byproducts enter systemic circulation from periodontal/peri-implant pockets that may in turn worsen insulin resistance by potentially augmenting low-grade inflammation [29-31]. Similarly, research indicates that increased blood $\mathrm{HbAlc}$ levels have an overall impact on the subgingival bacterial load [3234]. This suggests that the systemic load of peri-implant bacteria and their products is higher in individuals with persistent hyperglycemia compared to patients with wellcontrolled glycemic levels.

This study has some limitations that should be taken into consideration while evaluating the findings. This study only considered CBL around dental implants. Oth- er peri-implant clinical parameters such as peri-implant probing depth and attachment loss should also have been determined in order to establish the values of CBL as pathologic. Future observational studies should focus on the collection of peri-implant crevicular fluid to quantify the levels of cytokines from the areas of bone loss in both well- and poorly controlled T2DM patients. Moreover, cross-sectional studies should be performed for qualitative and quantitative assessment of microbial plaque around dental implants in well- and poorly controlled T2DM patients for better understanding of microbial pathology and to establish targeted therapeutic strategies.

\section{Conclusion}

Patients with poorly controlled T2DM present worse peri-implant bone outcome as compared to patients with well-controlled diabetes. Predictability of the outcomes of successful dental implant therapy depends on the maintenance of $\mathrm{HbAlc}$ levels.

\section{Acknowledgments}

This project was funded by King Abdullah International Medical Research Center, Ministry of National Guard, Health Affairs, Riyadh, Saudi Arabia. The authors thank Dr. Ali Al Ehaideb, Chairman, Dental Services and Department of Dental Services, Central Region, King Abdulaziz Medical City, Ministry of National Guard Health Affairs, Riyadh, Saudi Arabia, for facilitating this study.

\section{Disclosure Statement}

The authors declare that they have no conflicts of interests to disclose.

\section{References}

1 American Diabetes Association. Diagnosis and classification of diabetes mellitus. Diabetes Care. 2014 Jan;37 Suppl 1:S81-90.

2 Nathan DM, Kuenen J, Borg R, Zheng H Schoenfeld D, Heine RJ; A1c-Derived Average Glucose Study Group. Translating the A1C assay into estimated average glucose values. Diabetes Care. 2008 Aug;31(8):1473-8.

3 Dowell S, Oates TW, Robinson M. Implant success in people with type 2 diabetes mellitus with varying glycemic control: a pilot study. J Am Dent Assoc. 2007 Mar;138(3):355-61.

4 Robert AA, Al Dawish MA, Braham R, Musallam MA, Al Hayek AA, Al Kahtany NH. Type 2 diabetes mellitus in Saudi Arabia: major challenges and possible solutions. Curr Diabetes Rev. 2017;13(1):59-64.
80

Med Princ Pract 2019;28:75-81 DOI: $10.1159 / 00049511$
Al Zahrani/Al Mutairi 
5 Mealey BL, Oates TW; American Academy of Periodontology. Diabetes mellitus and periodontal diseases. J Periodontol. 2006 Aug; 77(8):1289-303.

6 Javed F, Romanos GE. Impact of diabetes mellitus and glycemic control on the osseointegration of dental implants: a systematic literature review. J Periodontol. 2009 Nov; 80(11):1719-30.

7 Shin DS, Park JW, Suh JY, Lee JM. The expressions of inflammatory factors and tissue inhibitor of matrix metalloproteinase- 2 in human chronic periodontitis with type 2 diabetes mellitus. J Periodontal Implant Sci. 2010 Feb;40(1):33-8.

8 Um YJ, Jung UW, Kim CS, Bak EJ, Cha JH, Yoo YJ, et al. The influence of diabetes mellitus on periodontal tissues: a pilot study. J Periodontal Implant Sci. 2010 Apr;40(2):4955.

9 Francis-Sedlak ME, Uriel S, Larson JC, Greisler HP, Venerus DC, Brey EM. Characterization of type I collagen gels modified by glycation. Biomaterials. 2009 Mar;30(9):1851-6.

10 Méndez JD, Xie J, Aguilar-Hernández M, Méndez-Valenzuela V. Trends in advanced glycation end products research in diabetes mellitus and its complications. Mol Cell Biochem. 2010 Aug;341(1-2):33-41.

11 Weber HP, Crohin CC, Fiorellini JP. A 5-year prospective clinical and radiographic study of non-submerged dental implants. Clin Oral Implants Res. 2000 Apr;11(2):144-53.

12 Abrahamsson I, Berglundh T, Moon IS, Lindhe J. Peri-implant tissues at submerged and non-submerged titanium implants. J Clin Periodontol. 1999 Sep;26(9):600-7.

13 Oates TW Jr, Galloway P, Alexander P, Vargas Green A, Huynh-Ba G, Feine J, et al. The effects of elevated hemoglobin $A(1 c)$ in patients with type 2 diabetes mellitus on dental implants: survival and stability at one year. J Am Dent Assoc. 2014 Dec;145(12):1218-26.

14 Eskow CC, Oates TW. Dental implant survival and complication rate over 2 years for individuals with poorly controlled type 2 diabetes mellitus. Clin Implant Dent Relat Res. 2017 Jun;19(3):423-31.

15 von Elm E, Altman DG, Egger M, Pocock SJ, Gøtzsche PC, Vandenbroucke JP; STROBE Initiative. The Strengthening the Reporting of Observational Studies in Epidemiology (STROBE) Statement: guidelines for reporting observational studies. Int J Surg. 2014 Dec;12(12):1495-9.
16 Renvert S, Persson GR, Pirih FQ, Camargo PM. Peri-implant health, peri-implant mucositis, and peri-implantitis: case definitions and diagnostic considerations. J Clin Periodontol. 2018 Jun;45 Suppl 20:S278-85.

17 Meredith N, Book K, Friberg B, Jemt T, Sennerby L. Resonance frequency measurements of implant stability in vivo. A cross-sectional and longitudinal study of resonance frequency measurements on implants in the edentulous and partially dentate maxilla. Clin Oral Implants Res. 1997 Jun;8(3):226-33.

18 García-García M, Mir-Mari J, Benic GI, Figueiredo R, Valmaseda-Castellón E. Accuracy of periapical radiography in assessing bone level in implants affected by peri-implantitis: a cross-sectional study. J Clin Periodontol. 2016 Jan;43(1):85-91.

19 Anner R, Grossmann Y, Anner Y, Levin L. Smoking, diabetes mellitus, periodontitis, and supportive periodontal treatment as factors associated with dental implant survival: a long-term retrospective evaluation of patients followed for up to 10 years. Implant Dent. 2010 Feb;19(1):57-64.

20 Mombelli A, Cionca N. Systemic diseases affecting osseointegration therapy. Clin Oral Implants Res. 2006 Oct;17(S2 Suppl 2):97103.

21 Kirk JK, Bell RA, Bertoni AG, Arcury TA, Quandt SA, Goff DC Jr, et al. Ethnic disparities: control of glycemia, blood pressure, and LDL cholesterol among US adults with type 2 diabetes. Ann Pharmacother. 2005 Sep;39(9): 1489-501.

22 Ghiraldini B, Conte A, Casarin RC, Casati MZ, Pimentel SP, Cirano FR, et al. Influence of Glycemic Control on Peri-Implant Bone Healing: 12-Month Outcomes of Local Release of Bone-Related Factors and Implant Stabilization in Type 2 Diabetics. Clin Implant Dent Relat Res. 2016 Aug;18(4):801-9.

23 Oates TW, Dowell S, Robinson M, McMahan CA. Glycemic control and implant stabilization in type 2 diabetes mellitus. J Dent Res. 2009 Apr;88(4):367-71.

24 Akram Z, Abduljabbar T, Abu Hassan MI, Javed $\mathrm{F}$, Vohra F. Cytokine profile in chronic periodontitis patients with and without obesity: A systematic review and meta-analysis. Dis Markers. 2016;2016:4801418.
25 Akram Z, Rahim ZH, Taiyeb-Ali TB, Shahdan MS, Baharuddin NA, Vaithilingam RD, et al. Resistin as potential biomarker for chronic periodontitis: A systematic review and metaanalysis. Arch Oral Biol. 2017 Jan;73:311-20.

26 Liu R, Bal HS, Desta T, Krothapalli N, Alyassi $\mathrm{M}$, Luan $\mathrm{Q}$, et al. Diabetes enhances periodontal bone loss through enhanced resorption and diminished bone formation. J Dent Res. 2006 Jun;85(6):510-4.

27 Ribeiro FV, de Mendonça AC, Santos VR, Bastos MF, Figueiredo LC, Duarte PM. Cytokines and bone-related factors in systemically healthy patients with chronic periodontitis and patients with type 2 diabetes and chronic periodontitis. J Periodontol. 2011 Aug;82(8): 1187-96.

28 Al-Sowygh ZH, Ghani SM, Sergis K, Vohra F, Akram Z. Peri-implant conditions and levels of advanced glycation end products among patients with different glycemic control. Clin Implant Dent Relat Res. 2018 Jun;20(3):34551.

29 Salvi GE, Carollo-Bittel B, Lang NP. Effects of diabetes mellitus on periodontal and peri-implant conditions: update on associations and risks. J Clin Periodontol. 2008 Sep;35(8 Suppl):398-409.

30 Al Amri MD, Kellesarian SV, Al-Kheraif AA, Malmstrom H, Javed F, Romanos GE. Effect of oral hygiene maintenance on $\mathrm{HbAlc}$ levels and peri-implant parameters around immediately-loaded dental implants placed in type2 diabetic patients: 2 years follow-up. Clin Oral Implants Res. 2016 Nov;27(11):1439-43.

31 Levine RS. Obesity, diabetes and periodontitis-a triangular relationship? Br Dent J. 2013 Jul;215(1):35-9.

32 Naguib G, Al-Mashat H, Desta T, Graves DT. Diabetes prolongs the inflammatory response to a bacterial stimulus through cytokine dysregulation. J Invest Dermatol. 2004 Jul;123(1): 87-92.

33 Makiura N, Ojima M, Kou Y, Furuta N, Okahashi N, Shizukuishi S, et al. Relationship of Porphyromonas gingivalis with glycemic level in patients with type 2 diabetes following periodontal treatment. Oral Microbiol Immunol. 2008 Aug;23(4):348-51.

34 Miranda TS, Feres M, Retamal-Valdés B, Perez-Chaparro PJ, Maciel SS, Duarte PM. Influence of glycemic control on the levels of subgingival periodontal pathogens in patients with generalized chronic periodontitis and type 2 diabetes. J Appl Oral Sci. 2017 Jan-Feb; 25(1):82-9. 